\title{
Traceability of meat products - application of DNA technology
}

\author{
M.L. TATE \\ AgResearch, Invermay, P.O. Box 50034, Mosgiel \\ mike.tate@agresearch.co.nz
}

\begin{abstract}
Traceability requirements for market access, food safety and disease control are a key issue in the meat industry. Traceability also offers new opportunities for market-lead product improvement and genetic selection. DNA technology has recently provided a solution to the problem of tracing meat cuts from overseas markets back to the New Zealand processor's carcass record and the farm of origin. The DNA system involves storing a sample of every carcass processed, and using forensic DNA matching to identify the ensuing meat cuts. While the system has solved one aspect of traceability, significant challenges remain to provide cost effective meat traceability for market assurance and product improvement.
\end{abstract}

Keywords: animal welfare, consumers, DNA, market access, traceability

\section{Introduction}

Consumers expect cheap, but safe food. In the last 10 years, media coverage of fatalities linked to consumption of animal products has raised consumer concerns. For example, many consumers were shocked to hear of the "unnatural" livestock feeding practices which turned ruminants into carnivores, enabling "mad cow" BSE (bovine spongiform encephalopathy) to propagate in Europe. Analysis of such food "crises" has highlighted the lack of specific information on the origin of meat, movement of stock and the feed and other inputs by which animals are raised. Processors, retailers, consumers and governments need to trace animals and inputs to meat product (Phillips et al. 2000).

The primary reason for traceability is to allay consumer concerns over unsafe practice and to quickly isolate, contain and recall product when a health issue is identified. Specific examples of product recall include identification of food with serious bacterial contamination (e.g., Escherichia coli VTEC O157), or product from contaminated land (e.g., Chernobyl radioactivity, organophosphate pesticides). Control of animal health is a second key reason for individual animal traceability.
This may be purely for animal welfare, productivity and market access reasons (e.g., foot and mouth disease) or because the animal disease is transmissible to human (e.g., tuberculosis) (Pettitt 2001).

In addition to managing risk, the traceability systems provide new opportunities. With traceable product, positive actions to improve animal heath, food safety or environmental sustainability can become part of brand values and marketing (e.g., organic or environmentally sustainable brands). Finally, traceability offers the potential for feedback of individual product information from the market to the processor (carcass of origin), the farmer (animal of origin) and the breeder of livestock (sire and dam). Such specific feedback has the potential to accelerate a cycle of consumer driven product improvement. This is a key component in achieving the much-espoused goal of differentiating high value brands from commodity product.

Achieving traceability through traditional recording systems has proved a challenge. Individual identity and inputs must be recorded through the life of an animal, during slaughter and dismemberment and through secondary processing to the market. Processors, in particular, face a major challenge to trace all products through dismemberment, and manufacturing processes. Hundreds of separate products can be produced from a single animal including meat cuts, offal, hide and byproducts. To be cost effective, production speed and flexibility must be maintained (for example, nine sheep per minute with the flexibility to process to hundreds of product specifications).

In addition to the obvious technologies of tags, barcodes, databases and electronic identification (EID), DNA technologies have the potential to solve some of the challenges of animal traceability. AgResearch has recently developed a system for meat traceability. This system is described, and the advantages and limitations of DNA meat traceability technology are discussed.

\section{DNA identification}

The practice of DNA identification is well established in legal and forensic casework. In animals, the process of DNA analysis is very similar and methods are available for all common pastoral livestock including, 
sheep, cattle, goats and deer. Typically these methods identify variable regions of DNA termed simple tandem repeats (STR) or microsatellite DNA. Hundreds of such variable regions have been described in livestock but only five to ten such regions need to be tested to individually identify an animal within a population of tens of millions. Identical twins and clones are the rare exceptions to unique DNA identification of individuals; these typically have identical DNA profiles. DNA tests can be routinely carried out from a swab of tissue, hair follicles or a drop of blood. Methods are available for long-term room temperature, storage of samples prior to DNA analysis (Cunningham \& Meghen 2001).

\section{A system for DNA traceability of meat products}

Lamb has been exported from New Zealand to the United Kingdom for nearly a century. Only in the last 3 years has a system been implemented by a major food exporter to trace lamb in the market back to specific carcass information and the farm of origin in New Zealand. This easiTrace ${ }^{a ̈}$ DNA traceability system is outlined in Figure 1 and described below.

A blood sample is collected from the neck of each carcass, on an easiTrace ${ }^{a}$ DNA-label, prior to the carcass entering the cutting room. The label is constructed to store and preserve DNA. Each label has an aggressive adhesive backing, with which it is securely positioned on the printed identification ticket of the carcass. As protection against samples being altered, the label has a built-in tamper indicator. Just prior to dismemberment, carcass tickets, with their attached DNA-labels, are collected, batched, labelled (date and time), boxed, and stored using the processor's inventory system.

After processing, meat cuts are packaged and the cuts and/or cartons are labelled with the date and time of manufacture. When a trace is required, the distributor or retailer collects a sample from the meat cut and forwards it to the laboratory along with packing information from the carton label. The packing

Figure 1 DNA traceability system schema.

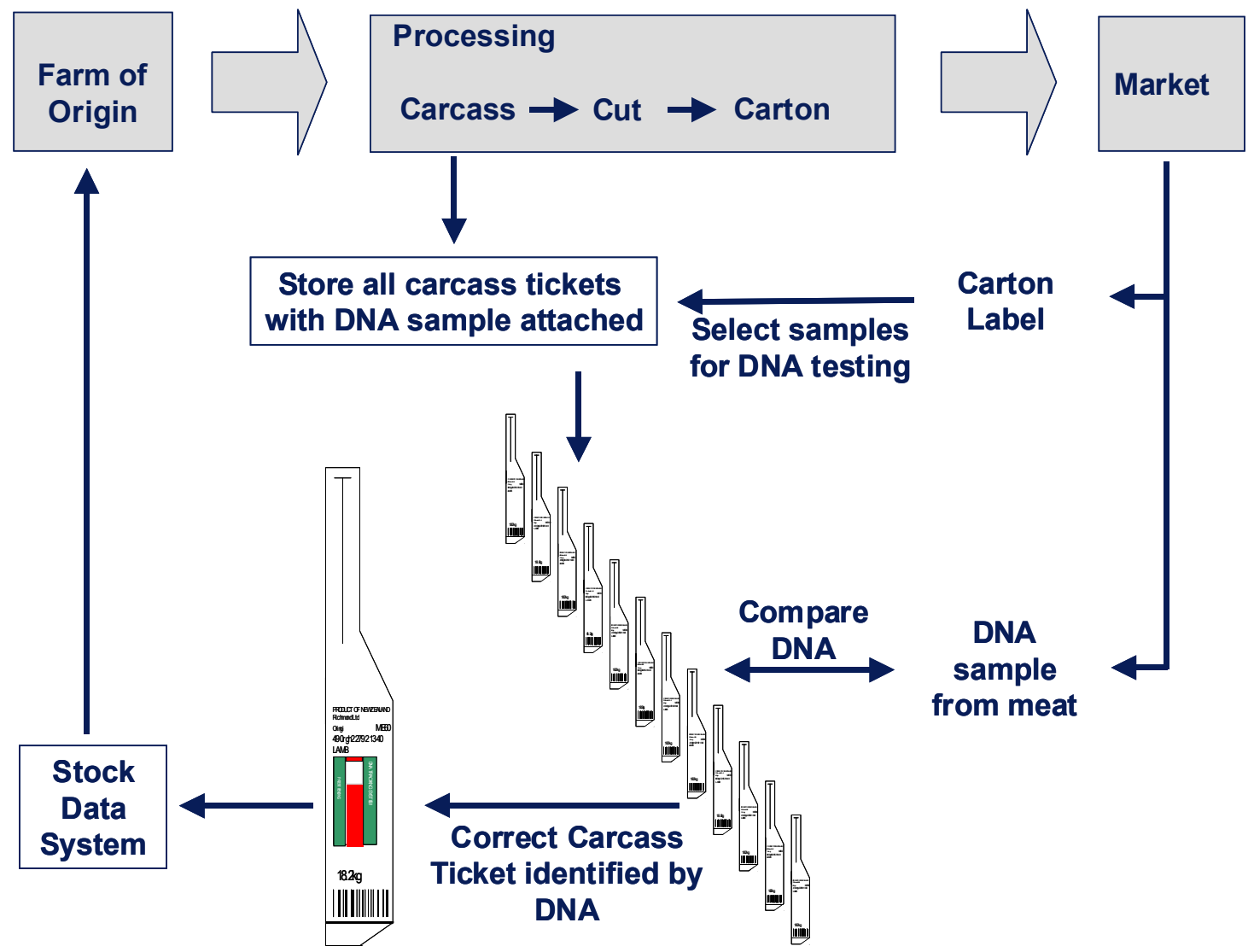


information is used to identify both the range of carcasses that could have possibly contributed to the meat cut (e.g., all carcasses cut by the morning shift) and, within this, the 'most likely' range (e.g., carcasses cut between 10.00am and 10.15am). DNA profiles from the selected carcass tickets are compared with the DNA profile from the meat sample, and an exact match identified. Following matching, the supplier of the animal carcass is identified from the carcass information in the processor's database.

To date, easiTrace ${ }^{a}$ has been applied to over one million animals. Shackell et al. (2001) present case studies of successfully traced meat cuts.

\section{Advantages and limitations of DNA tracing}

DNA systems have some key advantages for traceability:

1. DNA is an integral part of the food product. DNA identity cannot be destroyed without destroying the product.

2. DNA gives a very high standard of proof from a third party (DNA testing laboratory) that is difficult to match with intra-company paper or data records.

3. DNA traceability is simple to implement because it only involves taking and storing a sample. This does not interfere with workflow or require restructuring of processing procedures.

4. DNA profiles are inherited genetically and contain other information, for example, parentage, breed, species, presence or absence of specific gene variants.

One of the main limitations of current DNA systems is that results are not immediately available; the process of locating and shipping samples and then conducting DNA analysis can take days. This could be a drawback if rapid response is required in a product recall situation. A second limitation is the expense of DNA profiling. While sample archiving is routine, current systems only trace animals on an audit or "as required" basis. As technology reduces the cost of DNA profiling, this situation may change.

DNA systems will only work well with accurate batch recording so that (1) the DNA search is limited to relatively few samples and (2) if no DNA match is found, a company can categorically state the product is not from their system. To some extent a good batch recording system limits the impact of the lack of immediacy in DNA tracing. Immediate recall decisions can be made on batch information, with individualisation from DNA refining this process at a later date.

\section{Future challenges}

DNA identification can solve the problem of meat traceability during high throughput processing and assure the ultimate origin of product. This, however, does not account for every movement and transaction involving the animal or product, between the times the reference and test samples were taken. While tags and electronic systems are effective on packaged product, there are, arguably, significant developments required to produce foolproof and cost effective animal traceability systems. Ultimately new biometric solutions such as optical scanning identification (e.g., Optibrand ${ }^{\mathrm{TM}}$, www.optibrand.com) may provide cheap and tamperproof solutions to tracking animal movements.

Manufactured products such as "ready meals" or sausages offer one of the greatest remaining challenges for meat traceability. In the future, DNA technologies may provide some solutions via micro-extraction of DNA or deconvolution of mixed DNA to obtain a profile of each contributing animal.

Finally, social and economic drivers and human behaviour remain a significant challenge. Any traceability system, no matter how carefully constructed can be circumvented. In this context, it is important that traceability systems are not simply imposed as a cost but are built to provide commercial value and feedback for producers and processors willing to modify practices, or breed animals to valued market requirements.

\section{References}

Cunningham E.P.; Meghen C.M. 2001. Biological identification systems: genetic markers. pp. 491499. In: Revue scientifique et technique d'office international des epiozooties 20: traceability of animals and products.

Phillips N; Bridgeman J; Ferguson-Smith M. 2000. The BSE inquiry, volume 1: findings and conclusions. The Stationary Office, Norwich, 308 pp. Website: http://www.bseinquiry.gov.uk/report/ volume $1 /$ toc.htm.

Shackell, G.H.; Tate, M.L.; Anderson R.M. 2001. Installing a DNA based traceability system in the meat industry. Proceedings of the Association for the Advancement of Animal Breeding and Genetics 14: 553-556.

Pettitt R.G. 2001. Traceability in the food animal industry and supermarket chains. pp. 584-597. In: Revue scientifique et technique d'office international des epiozooties 20: traceability of animals and products. 